\title{
BMJ Open Association between different coping styles and health-related quality of life in people with Parkinson's disease: a cross-sectional study
}

\author{
Jenny Doris Liebermann, ${ }^{1}$ Otto W. Witte, ${ }^{1,2}$ Tino Prell (ib) ${ }^{1,2}$
}

To cite: Liebermann JD, Witte OW, Prell T. Association between different coping styles and health-related quality of life in people with Parkinson's disease: a crosssectional study. BMJ Open 2020;10:e036870. doi:10.1136/ bmjopen-2020-036870

- Prepublication history for this paper is available online. To view these files, please visit the journal online (http://dx.doi. org/10.1136/bmjopen-2020036870).

Received 08 January 2020

Revised 24 May 2020

Accepted 27 May 2020

\section{Check for updates}

(c) Author(s) (or their employer(s)) 2020. Re-use permitted under CC BY-NC. No commercial re-use. See rights and permissions. Published by BMJ.

${ }^{1}$ Department of Neurology, Jena University Hospital, Jena, Germany

${ }^{2}$ Center for Healthy Ageing, Jena University Hospital, Jena, Germany

Correspondence to

Dr Tino Prell;

tino.prell@med.uni-jena.de

\section{ABSTRACT}

Objective To describe overlapping coping strategies in people with Parkinson's disease.

Design Cross-sectional, cohort study.

Setting Monocentric, inpatient and outpatient, university hospital.

Participants Two-hundred participants enrolled, 162 patients with Parkinson's disease (without dementia) analysed.

Primary and secondary outcome measures Prevalence of different coping styles according to the German Essen Coping Questionnaire. Association between coping, sociodemographic and clinical parameters (Movement Disorder Society (MDS)-sponsored revision of the Unified Parkinson's Disease Rating Scale (UPDRS), non-motor symptoms questionnaire (NMS-Quest), Montreal cognitive assessment (MoCA), Beck depression inventory (BDI) and health-related quality of life (Short Form Health Survey 36 (SF-36))).

Results In comparison with patients who employed a passive coping style, patients using an active form of coping were characterised by a shorter disease duration $(p=0.017)$, fewer motor impairments (MDS-UPDRS ॥ $p=0.040$, MDS-UPDRS III $p=0.003$ ), a lower non-motor burden (NMS-Quest $p=0.048$ ), better cognitive function (MoCA $\mathrm{p}=0.036$ ) and fewer depressive symptoms (BDI $\mathrm{p}<0.001)$. From the 162 participants, $24 \%$ showed an overlap of active and passive coping strategies. The most common combination was acting/problem-oriented coping and distance and self-promotion. In comparison with patients who employed passive coping, the group with an overlapping coping style was characterised by a shorter disease duration $(p=0.023)$ and lower depressive burden $(p=0.001)$. In comparison with patients who employed active coping, the overlap group was characterised by poorer cognitive function $(p=0.045)$. The SF-36 values of the overlap group were between those of the active and passive coping groups.

Conclusion Knowledge about overlapping coping strategies is relevant to the implementation of strategies to promote active and healthy coping.

\section{INTRODUCTION}

The complex motor and non-motor symptoms of Parkinson's disease (PD) affect daily living and the ability to engage in everyday
Strengths and limitations of this study

- The study addressed coping with Parkinson's disease and examined psychological factors and health-related quality of life associated with different coping strategies.

- The study examined overlapping active and passive coping strategies in Parkinson's disease by using a detailed German coping questionnaire.

- The studied cohort included patients from a specialised movement disorder unit in a university hospital, limiting the generalisability to community dwelling people with Parkinson's disease.

- Cross-sectional design does not allow conclusions about changes of coping during disease course.

- Cross-sectional design can only imply association, not causation.

activities. The progressive nature of the disease means living with the experience of continuous loss of independence. ${ }^{1}$ This requires the development of individual strategies to cope with disease-related impairments to maintain an active everyday life. Several studies using coping questionnaires have demonstrated that the individual's coping strategy in PD may be associated with personality, depression, cognition and quality of life..$^{2-4}$ Because patients with PD are unable to recover from their persisting condition, they have to find strategies to adapt to the progressive functional impairment in order to maintain quality of life. In general, active and passive coping strategies were regarded as separate entities. In contrast to active coping strategies, which focus on changing environmental aspects, the passive strategies refer to feeling of helplessness to deal with the stressor. ${ }^{5}$ This reliance on external resources in passive coping is contrasted with active coping. Active coping is commonly associated with better health, while passive coping is associated with greater depression and greater functional 
impairment. ${ }^{6}$ In PD, passive coping was found to be associated with poorer health-related quality of life and poorer physical health. ${ }^{7-12}$ While most coping research in PD has concentrated on the distinction between active and passive coping, ${ }^{8913-15}$ little attention was paid to mixed or overlapping coping strategies in PD. We hypothesised that coping strategies line on a continuum rather than in strict categories in one individual and that persons with PD use several forms of coping strategies, to varying degrees, at the same time. Thus, the current study aimed to determine the prevalence of different coping strategies (active, passive, mixed) in people with PD attending a movement disorder centre in a university hospital. The second aim was to replicate the association among clinical parameters, health-related quality of life and coping.

There are two methods for the assessment of coping in the German-speaking region that are mostly used: the Freiburg Coping Questionnaire (Freiburger Fragebogen zur Krankheitsverarbeitung) and the Trier Coping Scales (Trierer Skalen zur Krankheitsbewältigung). Both have their psychometric limitations and are critically discussed in literature. ${ }^{16}$ We therefore used the Essen Coping Questionnaire (ECQ) that specifically assesses the characteristics of the individual coping with a disease. While the ECQ was so used in several chronic diseases, it has not been used in PD so far.

\section{METHODS}

\section{Design and participants}

This was a cross-sectional, monocentric cohort study in patients with PD attending a movement disorder unit at a university hospital. All patients gave their written informed consent. Data from patients were collected either during their visit to the outpatient clinic (specialised on PD, $\mathrm{n}=42$ ) or during their stay on the neurological PD ward $(n=158)$ in the Department of Neurology at the Jena University Hospital between May 2017 and September 2018. All the patients on the neurological ward received a multimodal treatment by specialised therapists and medication modifications during their stay in the hospital (German Multimodale Komplexbehandlung bei Morbus Parkinson). ${ }^{17}$ Reasons for inpatient admission or appointment to our specialised outpatient clinic were therefore, among others, an increase of fluctuations, worsening of dyskinesias, increase of off phases, evaluation for deep brain stimulation and worsening of gait and freezing. The inclusion criterion was PD diagnosis according to the Movement Disorder Society (MDS) diagnostic criteria. The exclusion criteria were cerebrovascular disorders, deep brain stimulation, levodopa/carbidopa enteral infusion, apomorphine infusion, delirium and PD dementia. All tests were conducted during the medication $\mathrm{ON}$ phase.

Two-hundred patients were enrolled into the study. Overall 38 patients were excluded from analysis due to missing data $(n=9)$ or PD dementia $(n=29)$.

\section{Assessments}

The following demographic data were collected by selfreport: age, sex, marital status (single/divorced/widowed or married) and level of education (high: German Abitur or University; medium: German Real Schule; low: German Hauptschule; or no schooling). Several clinical parameters were recorded by a PD specialised nurse: the MDS-sponsored revision of the Unified Parkinson's Disease Rating Scale (MDS-UPDRS) ${ }^{18}$ the revised nonmotor symptoms questionnaire (NMS-Quest) and Hoehn $\&$ Yahr staging were used to evaluate motor and nonmotor symptoms. The MDS-UPDRS included non-motor aspects of daily living (I), motor aspects of daily living (II), standardised motor examination (III), motor complications (dyskinesia, motor fluctuations and dystonia, IV). The distinct PD subtypes (postural instability and gait difficulty-predominant type (PIGD); indeterminate/ mixed type and tremor-type) were calculated from the MDS-UPDRS as described previously. ${ }^{19}{ }^{20}$ Cognition was assessed with the Montreal cognitive assessment (MoCA; obtained by trained neuropsychologist) and PD dementia was defined as a MoCA $<21$ points. ${ }^{21}$ The Beck depression inventory (BDI) was used to assess the burden of depressive symptoms (self-report), and depression was defined as BDI $>15 .^{22}$ The German Short Form 36 v0.1 (SF-36; self-report) was used to measure health-related quality of life. The SF-36 comprises eight health profile score scales: physical functioning, physical role, bodily pain, general health, vitality, social functioning, emotional role and mental health. We calculated single-dimension scores according to the predefined standardised scoring algorithms by following the manual instructions. ${ }^{23}$ Coping was assessed by using self-report ECQ. ${ }^{24}$ It examines a person's strategies used to cope with disease on the emotional, cognitive and behavioural levels. The questionnaire comprises 45 questions and is represented by 9 scales, each comprising 5 items scored on a 5 -tier scale $(0=$ 'not at all' to $4=$ 'extremely'). The ECQ describes the following areas: (1) acting and problem-oriented coping, (2) distance and self-promotion, (3) information seeking and exchange of experiences, (4) trivialisation, wishful thinking and defence, (5) depressive processing, (6) willingness to accept help, (7) active search for social integration, (8) trust in medical care and (9) finding of inner stability. For test evaluation, values were summed across items of the individual scales and then divided by the number of items.

\section{Statistical analysis}

The SPSS statistical computer package (V.25.0; IBM Corporation) was used for all statistical analyses. Values are given as the mean and SD when normally distributed and otherwise as median and IQR. Categorical variables are presented as numbers or percentages.

In the first step, descriptive statistics were used to describe the cohort and different coping styles according to the ECQ subscales. The correlation between ECQ subscales and clinical variables was tested using Pearson's 
Table 1 Demographical and clinical characteristics

$n=162$

\begin{tabular}{lrc}
\hline General demographics & & \\
Age (mean, SD; years) & 70.7 & 9.7 \\
Sex (n, \%) & & \\
\hline Female & 58 & 35.8 \\
Male & 104 & 64.2 \\
\hline
\end{tabular}

Marital status (n, \%)

\begin{tabular}{|c|c|c|}
\hline Single & 4 & 2.5 \\
\hline Married & 88 & 54.3 \\
\hline Divorced/widowed & 25 & 15.4 \\
\hline Missing data & 45 & 27.8 \\
\hline \multicolumn{3}{|l|}{ Education (n, \%) } \\
\hline Middle school (German Realschule) & 43 & 26.5 \\
\hline High school (German Abitur, study) & 53 & 32.7 \\
\hline $\begin{array}{l}\text { Lower education level (German Hauptschule, } \\
\text { no school) }\end{array}$ & 22 & 13.6 \\
\hline Missing data & 44 & 27.2 \\
\hline \multicolumn{3}{|l|}{ Professional activity (n, \%) } \\
\hline Pensioned & 113 & 69.8 \\
\hline Employed & 6 & 3.7 \\
\hline Missing data & 43 & 26.5 \\
\hline \multicolumn{3}{|l|}{ Coping (ECQ) } \\
\hline Acting, problem-oriented coping (mean, SD) & 2.10 & 0.94 \\
\hline $\begin{array}{l}\text { Distance and self-promotion } \\
\text { (mean, SD) }\end{array}$ & 1.85 & 0.83 \\
\hline $\begin{array}{l}\text { Information seeking and exchange of } \\
\text { experiences (mean, SD) }\end{array}$ & 1.56 & 0.96 \\
\hline $\begin{array}{l}\text { Trivialisation, wishful thinking and defence } \\
\text { (mean, SD) }\end{array}$ & 1.29 & 0.74 \\
\hline Depressive processing (mean, SD) & 0.91 & 0.70 \\
\hline $\begin{array}{l}\text { Willingness to accept help } \\
\text { (mean, SD) }\end{array}$ & 1.48 & 0.66 \\
\hline Active search for social integration (mean, SD) & 1.57 & 0.86 \\
\hline Trust in medical care (mean, SD) & 1.96 & 0.52 \\
\hline Finding of inner stability (mean, SD) & 1.03 & 0.66 \\
\hline \multicolumn{3}{|l|}{ Parkinson's disease characteristics } \\
\hline Disease duration (mean, SD; years) & 8.6 & 7.2 \\
\hline Hoehn and Yahr stage (median, IQR) & 3.0 & 0 \\
\hline MDS-UPDRS I (mean, SD) & 12.7 & 7.8 \\
\hline MDS-UPDRS II (mean, SD) & 16.3 & 9.7 \\
\hline MDS-UPDRS III (mean, SD) & 27.7 & 16.2 \\
\hline MDS-UPDRS IV (mean, SD) & 3.8 & 4.8 \\
\hline NMS-Quest (mean, SD) & 10.4 & 5.1 \\
\hline Montreal cognitive assessment (mean, SD) & 25.4 & 2.6 \\
\hline $\begin{array}{l}\text { Beck depression inventory II } \\
\text { (mean, SD) }\end{array}$ & 11.4 & 9.6 \\
\hline
\end{tabular}

Health-related quality of life (SF-36)

$\begin{array}{lll}\text { Physical function (mean, SD) } & 32.3 & 13.8 \\ \text { Role-physical (mean, SD) } & 33.1 & 12.3 \\ \text { Bodily pain (mean, SD) } & 40.1 & 10.7\end{array}$

Continued

\section{Table 1 Continued}

\begin{tabular}{lcr} 
& $\mathrm{n}=\mathbf{1 6 2}$ & \\
\hline General health (mean, SD) & 38.0 & 9.1 \\
Vitality (mean, SD) & 41.6 & 10.2 \\
Social function (mean, SD) & 37.9 & 14.3 \\
Role-emotional (mean, SD) & 35.4 & 18.0 \\
Mental health (mean, SD) & 43.1 & 11.5 \\
$\begin{array}{l}\text { Physical component summary } \\
\text { (mean, SD) }\end{array}$ & 32.7 & 4.3 \\
$\begin{array}{l}\text { Mental component summary } \\
\text { (mean, SD) }\end{array}$ & 35.7 & 6.4 \\
\hline
\end{tabular}

ECQ, Essen Coping Questionnaire; MDS-UPDRS, Movement Disorder Society Unified Parkinson's Disease Rating Scale; NMS-Quest, nonmotor symptoms questionnaire; SF-36, Short Form Health Survey 36.

correlation for normally distributed and Spearman's correlation for non-normally distributed data. Group comparisons of clinical variables between two groups were performed with a t-test for normally distributed and a Mann-Whitney U test for non-normally distributed data. For group comparisons with more than two groups, analysis of variance for normally distributed data and the Kruskal-Wallis test for non-normally distributed data were used with the Dunn-Bonferroni test as a post hoc test. The $\chi^{2}$ test or Fisher's exact test was used to compare categorical variables.

A principal component analysis (PCA) with varimax rotation was used to extract the most important independent factors from the nine ECQ subscales. Only factors with eigenvalues $\geq 1$ were considered and only loadings greater than 0.4 were interpreted. All subscales had adequate communality scores. Examination of Kaiser's criteria and the scree plot yielded empirical justification for retaining two factors. For every patient, the regression coefficients for each factor were calculated as implemented in SPSS.

A logistic regression was then used to determine which clinical parameters were associated with the two PCA factors (active vs passive coping). Here, the parameters

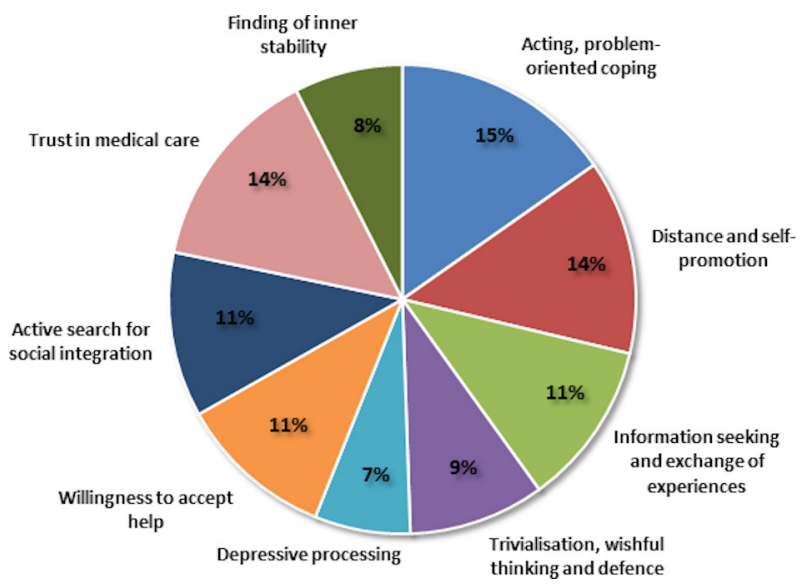

Figure 1 Frequency of used coping styles according to the Essen Coping Questionnaire subscales. 
Table 2 Correlation matrix for relationships between clinical variables and Essen Coping Questionnaire (ECQ) subscales

\begin{tabular}{|c|c|c|c|c|c|c|c|c|c|c|c|}
\hline \multirow[b]{2}{*}{$E C Q$} & & \multicolumn{10}{|c|}{ Clinical variables } \\
\hline & & Age & $\begin{array}{l}\text { Disease } \\
\text { duration }\end{array}$ & H\&Y & $\begin{array}{l}\text { MDS- } \\
\text { UPDRS I }\end{array}$ & $\begin{array}{l}\text { MDS- } \\
\text { UPDRS II }\end{array}$ & $\begin{array}{l}\text { MDS- } \\
\text { UPDRS III }\end{array}$ & $\begin{array}{l}\text { MDS- } \\
\text { UPDRS IV }\end{array}$ & NMS-Q & MoCA & BDI II \\
\hline APC & $p$ & 0.144 & 0.052 & 0.546 & 0.012 & 0.361 & 0.090 & 0.512 & 0.461 & 0.093 & $<0.001$ \\
\hline DSP & $r$ & -0.121 & -0.033 & 0.026 & -0.033 & 0.092 & -0.230 & 0.300 & 0.046 & 0.157 & -0.278 \\
\hline ISE & $p$ & 0.126 & 0.424 & 0.810 & 0.392 & 0.093 & 0.843 & 0.012 & 0.062 & 0.051 & 0.477 \\
\hline \multirow[t]{2}{*}{ TWD } & r & 0.030 & -0.051 & -0.014 & -0.089 & 0.052 & -0.139 & 0.136 & 0.028 & -0.096 & -0.143 \\
\hline & $p$ & 0.705 & 0.646 & 0.901 & 0.438 & 0.649 & 0.198 & 0.236 & 0.806 & 0.417 & 0.281 \\
\hline DP & $r$ & -0.083 & 0.352 & 0.144 & 0.427 & 0.371 & 0.257 & 0.252 & 0.342 & -0.185 & 0.594 \\
\hline \multirow[t]{2}{*}{ ASS } & r & -0.164 & -0.035 & -0.050 & -0.203 & -0.143 & -0.416 & 0.144 & -0.056 & 0.299 & -0.388 \\
\hline & $p$ & 0.039 & 0.755 & 0.664 & 0.074 & 0.208 & $<0.001$ & 0.209 & 0.625 & 0.010 & 0.002 \\
\hline \multirow[t]{2}{*}{ TMC } & $r$ & -0.076 & -0.247 & 0.246 & -0.042 & 0.139 & 0.033 & -0.058 & 0.072 & -0.232 & -0.160 \\
\hline & $p$ & 0.339 & 0.024 & 0.031 & 0.716 & 0.222 & 0.761 & 0.617 & 0.532 & 0.048 & 0.225 \\
\hline \multirow[t]{2}{*}{ FIS } & $r$ & -0.130 & 0.036 & -0.033 & 0.028 & -0.017 & -0.030 & 0.132 & 0.054 & 0.079 & -0.263 \\
\hline & $p$ & 0.101 & 0.745 & 0.777 & 0.805 & 0.880 & 0.784 & 0.249 & 0.640 & 0.507 & 0.004 \\
\hline
\end{tabular}

Bold values indicate significant correlations.

APC, acting/problem-oriented coping; ASS, active search for social integration; BDI, Beck depression inventory; DP, depressive processing; DSP, distance and self-promotion; FIS, finding of inner stability; H\&Y, Hoehn-Yahr Scale; ISE, information seeking and exchange of experiences; MDS-UPDRS, Movement Disorder Society Unified Parkinson Disease Rating Scale; MoCA, Montreal cognitive assessment; NMS-Q, non-motor symptoms questionnaire; TMC, trust in medical care; TWD, trivialisation, wishful thinking and defence; WAH, willingness to accept help.

showing significant differences between patients with active and passive coping were entered as independent variables into the logistic regression, namely disease duration, MDS-UPDRS I, II, III, NMS-Quest, education level, sex, presence of depression (BDI <or $>15)$ and MoCA.

A linear regression model was constructed with the mental component summary of the SF-36 as the dependent variable and the nine ECQ subscales as independent variables (Akaike's Information Criterion, stepwise forward selection).

To study patients with more than one dominant coping strategy (overlapping coping styles), two approaches were used. First, the highest and second highest ECQ subscales were determined and used to categorise patients according to the ECQ. Second, based on the PCA grouping into active and passive coping, we formed the overlap group that included all overlaps between the two coping forms and contained a sufficiently large sample. We defined the overlap group as regression factor active $\geq(0.9 *$ regression factor passive -0.5$)$ and regression factor active $\leq(0.9 *$ regression factor passive +0.5 ).

For all analyses, the significance level was set at $\mathrm{p}<0.05$.

\section{Patient and public involvement statement}

This research was done without patient involvement. Patients were not invited to comment on the study design and were not consulted to develop patient relevant outcomes or interpret the results. Patients were not invited to contribute to the writing or editing of this document for readability or accuracy.

\section{RESULTS}

\section{Demographic characteristics}

The final sample included $58(35.8 \%)$ female and 104 (64.2\%) male patients with PD (mean age $70 \pm 9.7$ years). The majority of patients were married, pensioners and had completed middle or high school education. The detailed clinical characteristics are provided in table 1 .

\section{Coping styles in PD}

The most frequently observed coping strategy was acting/ problem-oriented coping, followed by trust in medical care and distance and self-promotion. In contrast, emotional coping forms such as depressive processing and trivialisation, wishful thinking and defence achieved 
Table 3 Principal component analysis

\begin{tabular}{lcc}
\hline & \multicolumn{2}{c}{ Component } \\
\cline { 2 - 3 } ECQ subdomains & $\mathbf{1}$ & $\mathbf{2}$ \\
\hline Distance and self-promotion & 0.856 & \\
Acting/problem-oriented coping & 0.819 & \\
Active search for social integration & 0.794 & \\
Willingness to accept help & 0.703 & \\
Finding of inner stability & 0.687 & \\
Information seeking and exchange of & 0.644 & \\
experiences & & 0.897 \\
Trust in medical care & 0.552 & 0.590 \\
Depressive processing & & \\
Trivialisation, wishful thinking and & & 1.28 \\
defence & & 14.3 \\
\hline Eigen values for component & 3.93 & 0.71 \\
\hline Variance explained (\%) & 43.7 \\
\hline Cronbach's alpha & 0.80 & \\
\hline
\end{tabular}

ECQ, Essen Coping Questionnaire.

low mean ECQ values. Also finding inner stability was less frequently used in patients with PD. The distribution of the ECQ subscales is shown in figure 1.

A comparison with the control group of 1815 patients with other chronic diseases (chronic ophthalmic patients; chronic renal insufficiency patients; mixed sample of chronic patients of internal medicine, gynaecology, neurology and orthopaedics) described in the ECQ manual ${ }^{24}{ }^{25}$ showed that patients without PD most commonly use trust in medical care, followed by acting/problem-oriented coping and distance and self-promotion. Passive strategies such as depressive processing and trivialisation, wishful thinking and defence were less frequently used in these subjects. Our patients with PD showed lower mean ECQ values in almost all subgroups, especially those with active adaptive strategies such as acting/problem-oriented coping, distance and self-promotion, active search for social integration, trust in medical care and finding inner stability. Compared with the control group, patients with PD achieved higher values in the subdomains of passive coping strategies such as depressive processing and trivialisation, wishful thinking and defence.

\section{Association between coping styles and clinical factors}

Group comparisons and correlation analyses were performed to explore the influence of sociodemographic characteristics on coping. The mean values for each ECQ subdomain did not differ between male and female patients or between married and single persons. The ECQ values did not differ between inpatient and outpatient participants. In terms of education, group differences were found for the domain acting/problem-oriented coping between patients with middle (1.72 \pm 0.74$)$ and high education levels $(2.53 \pm 0.77 ; \mathrm{p}<0.001)$ and between patients with low $(1.97 \pm 1.03)$ and high education levels $(\mathrm{p}=0.025)$.

A higher MDS-UPDRS III was correlated with a lower level of distance and self-promotion and a lower active search for social integration. The burden of non-motor symptoms (NMS-Quest) correlated with depressive processing and willingness to accept help. The longer the disease persisted, the higher the depressive processing and the lower the trust in medical care. Of note, depression (BDI) was also correlated with disease duration $(\mathrm{p}=0.005$, $\mathrm{r}=0.421$ ). A higher burden of depressive symptoms (BDI) was correlated with lower acting/problem-oriented coping, lower distance and self-promotion, lower active searching for social integration, lower finding of inner stability, and higher depressive processing. Higher MoCA scores were correlated with higher acting/problemoriented coping and lower trust in medical care (table 2).

\section{Characteristics of active and passive coping}

Using PCA, two main components were extracted from the nine ECQ subscales: active and adaptive coping strategies load on component 1 , whereas rather passive and maladaptive coping strategies load on component 2. Overall, $58.03 \%$ of the total variance was explained. The sample size was adequate $(\mathrm{KMO}=0.803)$, and Bartlett's test of sphericity indicated that PCA was appropriate $\left(\chi^{2}(36)=539.515, \mathrm{p}<0.001\right)$. Table 3 shows the PCA structure matrix, components, eigenvalues and item loadings. Each patient was assigned to one of the two factors by using the regression coefficients for each factor. A total of 77 patients $(47.5 \%)$ were assigned to an active and 85 patients $(52.5 \%)$ to a passive coping strategy. Patients with an active coping style had a mean age of $69.65 \pm 10.12$ years and included 18 female $(28.1 \%)$ and 46 male $(71.9 \%)$ patients. In this group, the majority were married $(n=34$, $53.1 \%)$, pensioners $(\mathrm{n}=44,68.8 \%)$ and had a high level of education $(\mathrm{n}=32,50.0 \%)$. In comparison, the group that employed passive coping comprised 25 female (42.4 $\%)$ and 34 male $(57.6 \%)$ patients (mean age $71.50 \pm 9.74$ years). The majority of them were also married $(\mathrm{n}=29$, $49.2 \%)$ and pensioners $(n=40,67.8 \%)$. In the group that employed a passive coping strategy, the majority had a middle school education $(n=19,32.2 \%)$. Detailed results are shown in table 4 .

The passive form of coping was more common in female persons $\left(\chi^{2}(1)=4.645, \mathrm{p}=0.031\right)$ and in patients with a lower level of education $(\mathrm{p}=0.001)$. In comparison with patients who employed a passive coping style, patients using an active form of coping were characterised by a shorter disease duration $(\mathrm{p}=0.017)$, fewer motor impairments (MDS-UPDRS II $\mathrm{p}=0.040$, MDS-UPDRS III $\mathrm{p}=0.003$ ) and a lower non-motor burden (NMS-Quest $\mathrm{p}=0.048$, MDS-UPDRS I $\mathrm{p}<0.001$ ), better cognitive abilities (MoCA $\mathrm{p}=0.036$ ) and fewer depressive symptoms (BDI $\mathrm{p}<0.001$; table 4 ). The frequencies of active and passive coping styles did not differ between patients with tremor dominance (active: $\mathrm{n}=5,33.3 \%$; passive: $\mathrm{n}=10$, 
Table 4 Group comparison between patients with active and passive coping

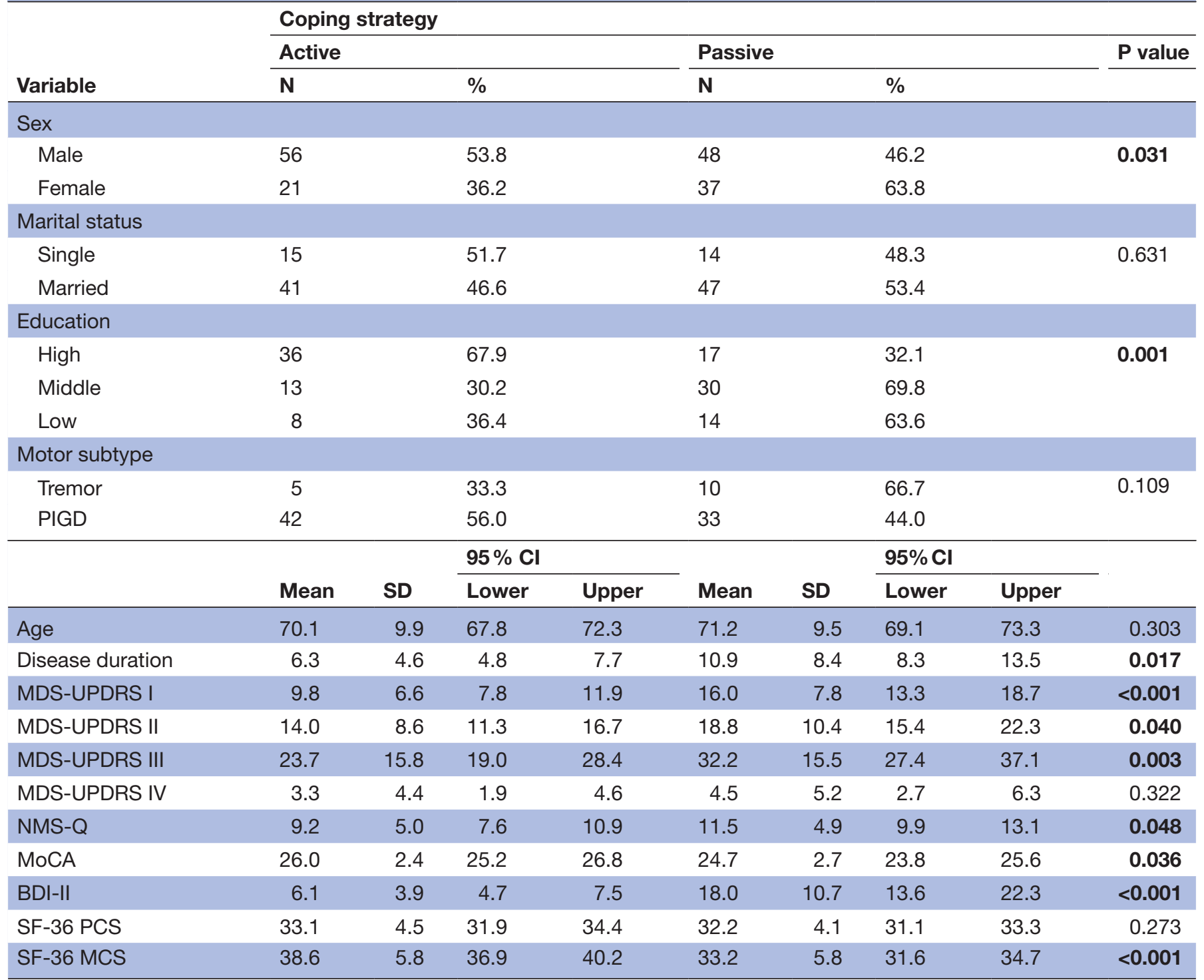

Bold values indicate significant results.

BDI, Beck depression inventory; MCS, mental component summary; MDS-UPDRS, Movement Disorder Society Unified Parkinson Disease Rating Scale; MoCA, Montreal cognitive assessment; NMS-Q, non-motors symptoms questionnaire; PCS, physical component summary; PIGD, postural instability/gait difficulty; SF-36, Short Form Health Survey 36.

$66.7 \%$ ) and patients with PIGD predominance (active: $\mathrm{n}=42,56.0 \%$; passive: $\mathrm{n}=33,44.0 \%$; $\mathrm{p}=0.145$ ).

The factors showing significant differences between patients with active and passive coping were entered as independent variables into a binary logistic regression model with active or passive coping style as the dependent variable. In the final model, depression $(\mathrm{OR}=0.03$, $\mathrm{p}=0.004)$ and longer disease duration $(\mathrm{OR}=1.30, \mathrm{p}=0.014)$ were associated with passive coping (Nagelkerkes $R^{2}=0.58$, $\mathrm{p}<0.001)$.

\section{Association with health-related quality of life}

We then examined the relationship between the ECQ subscales and the component summaries of the SF-36. Patients with an active coping style showed significantly higher mean values in the mental component summary $(\mathrm{p}<0.001)$ than patients with a passive coping strategy (table 4). There was no significant correlation between the ECQ subscales and the physical component summary. However, the mental component summary correlated moderately with depressive processing $(\mathrm{p}<0.001, \mathrm{r}=-0.417)$ and weakly with acting/problemoriented coping $(\mathrm{p}=0.001, \mathrm{r}=0.315)$, distance and selfpromotion $(\mathrm{p}=0.021, \mathrm{r}=0.222)$, active search for social integration $(\mathrm{p}=0.006, \mathrm{r}=0.264)$ and finding inner stability ( $\mathrm{p}=0.040, \mathrm{r}=0.198)$. In the linear regression, the mental component summary was associated with depressive processing $(\beta=0.66, p<0.001)$, active search for social integration $(\beta=0.17, p=0.029)$ and trivialisation, wishful thinking and defence $(\beta=0.16, p=0.036$; adjusted $\mathrm{R}^{2}=0.22, \mathrm{p}<0.001$ ). 


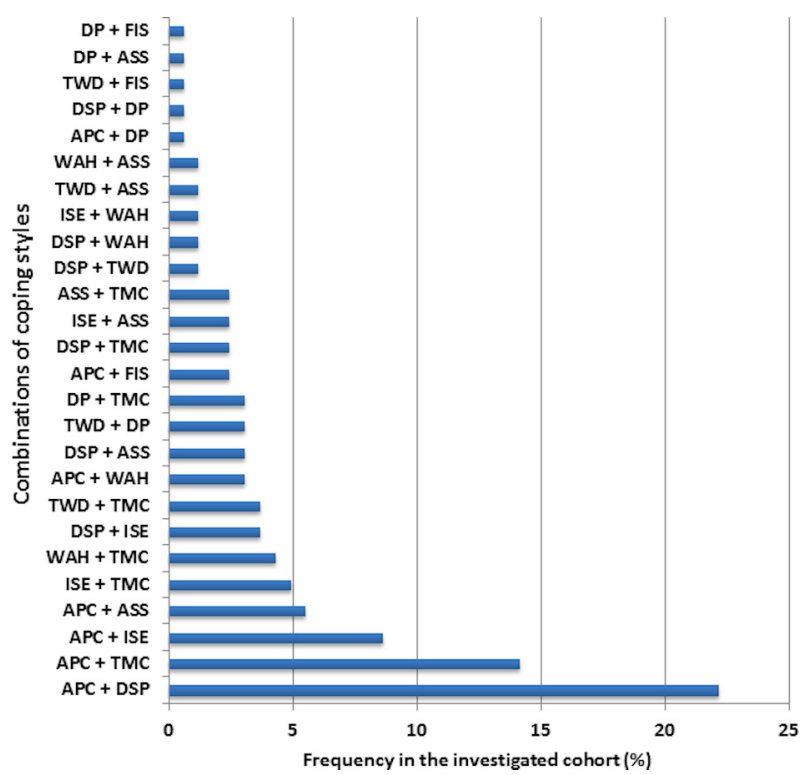

Figure 2 Combinations of the two most frequently used coping strategies. APC, acting, problem-oriented coping; ASS, active search for social integration; DP, depressive processing; DSP, distance and self-promotion; FIS, finding of inner stability; ISE, information seeking and exchange of experiences; TMC, trust in medical care; TWD; trivialisation, wishful thinking and defence; $\mathrm{WAH}$, willingness to accept help.

\section{Mixed coping styles}

Figure 2 shows that acting/problem-oriented coping with distance and self-promotion $(n=38,17.4 \%)$ was the most common combination of two different coping styles, followed by acting/problem-oriented coping and trust in medical care $(n=28,12.8 \%)$. Figure 3 shows a scatter plot of the regression factors for active and passive coping derived from the PCA. In particular, we were interested in the patients located in the transition zone between active and passive coping showing some overlap of active and passive coping. The overlapping group included 24 male $(61.5 \%)$ and 15 female $(38.5 \%)$ subjects. The majority

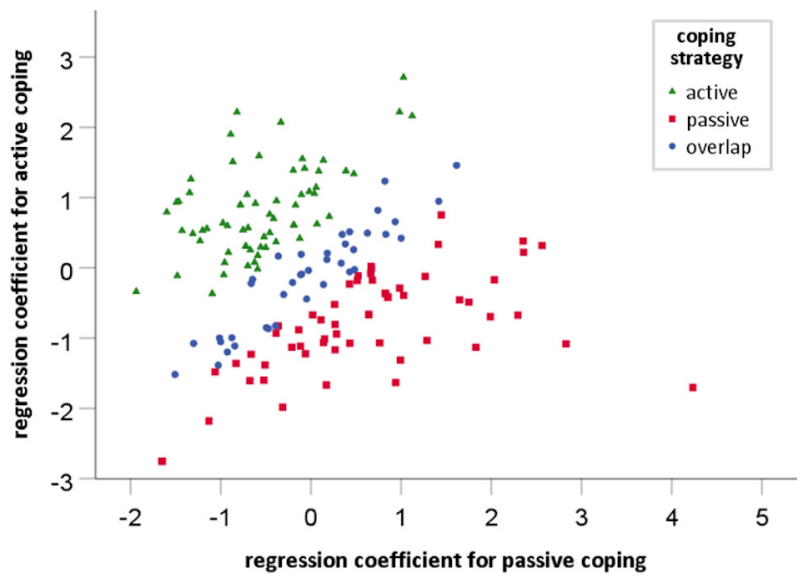

Figure 3 Scatter diagram of active, passive and mixed group. The degree of passive ( $x$-axis) and active (y-axis) coping is plotted against each other with higher values indicating higher passivity or activity, respectively.

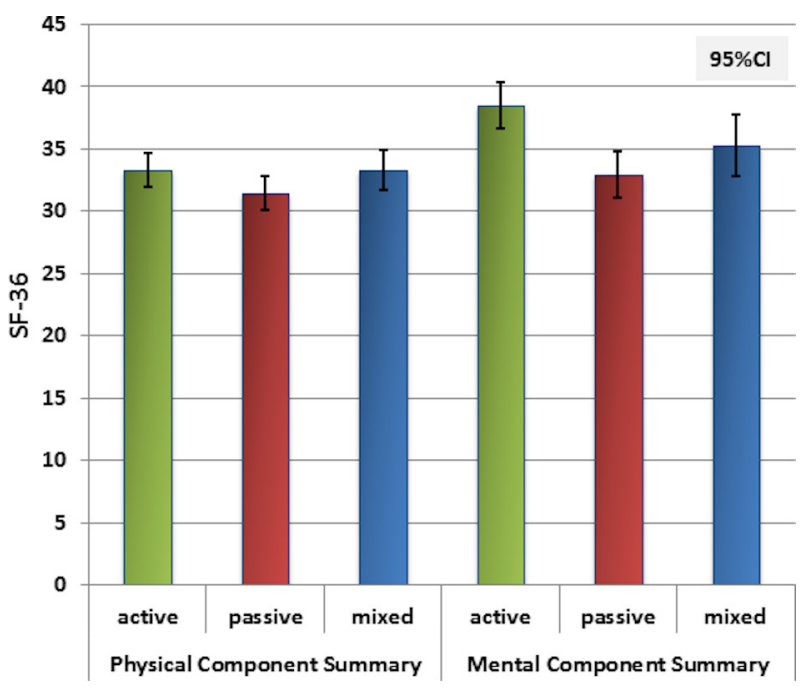

Figure 4 Short Form Health Survey 36 (SF-36) domains in patients with active, passive and mixed coping strategies.

were married $(\mathrm{n}=25,64.1 \%)$, pensioners $(\mathrm{n}=29,74.4 \%)$ and had a middle $(\mathrm{n}=16,41.0 \%)$ or high education level $(\mathrm{n}=13,33.3 \%)$. The most commonly used coping strategy in this group was acting/problem-oriented coping, followed by trust in medical care. Depressive processing and finding of inner stability were the least used. In comparison with patients who employed passive coping, the overlap group was characterised by a shorter disease duration (8.5 years, $\mathrm{SD}=6.8, \mathrm{p}=0.023$ ) and lower depressive burden (mean $\mathrm{BDI}=11.1, \mathrm{SD}=4.8, \mathrm{p}=0.001$ ). In comparison with patients who employed active coping, the overlap group was characterised by poorer cognitive function (mean MoCA=24.4, $\mathrm{SD}=2.4, \mathrm{p}=0.045$ ). The SF-36 values of the overlap group were between those of the active and passive coping groups (figure 4).

\section{DISCUSSION}

Our study confirms that patients with PD use all types of coping strategies to varying degrees. In line with former studies, the most common coping strategy was acting/ problem-oriented coping. ${ }^{2} 326-28$ Other studies have only addressed the question of which strategies are used most often or least. ${ }^{23} 262729$ However, our study demonstrates that patients with PD use more than one strategy. Many patients use several forms of coping at the same time. In our cohort, the combination of acting/problemoriented coping and distance and self-promotion was most commonly used. This means that patients with PD approach their disease management actively, in a problem-oriented and cognitively structured manner, while searching for encouragement and self-affirmation and use adaptive coping strategies. The second most common combination was acting/problem-oriented coping and trust in medical care. This means that trust in the work of physicians, in addition to active, problemoriented disease management, is of great importance for the coping with the disease in patients with PD. Also, in 
terms of the general categorisation into active and passive coping, we observed a minority of patients with an overlapping form of disease management. These patients with mixed coping strategies differed from those who employed active and passive coping in terms of cognitive function, depressive symptoms and disease duration. The overlap group was 'in between' active and passive coping groups in terms of disease duration and neuropsychiatric symptoms. Moreover, their health-related quality of life was between those of the active and passive groups. Given the exploratory nature of our study, future studies should evaluate in which aspects this entity of mixed coping strategies truly differ from other kinds of coping strategies and how this impacts quality of life.

Our study revealed some associations between clinical parameters, epidemiological factors and coping. Several studies using coping questionnaires and evaluation of clinical parameters have shown that the coping strategy in patients with PD can be associated with disease duration, the severity of motor and non-motor symptoms, cognition and depression. ${ }^{2} 3$ 26-28 30-32 Based on existing literature, our results confirmed that a longer disease duration, more severe limitations by motor and non-motor symptoms, and greater impairment by depressive symptoms promote passive and maladaptive coping strategies. The association between gender and coping are controversially discussed in the existing literature. We observed a gender-specific distribution of active and passive strategies, in concordance with previous studies. ${ }^{26} 33$ While men used both active and passive forms of coping to the same extent, women predominantly used passive coping strategies. However, the effect strength was low, so we do not assume that gender is a highly relevant factor for coping in patients with PD. We observed a correlation between education level and coping. In comparison with patients with lower or middle education levels, patients with high education level used more often acting/problem-oriented coping. Given that acting/ problem-oriented coping is associated with better healthrelated quality of life, one might conclude that patients with lower education levels require special attention and counselling to promote active and adaptive coping strategies. However, in logistic regression, education level was no significant predictor of active or passive coping. Therefore, the hypothesis of an association between a higher education level and active coping should be evaluated in further confirmatory studies.

Several studies have already addressed the association between quality of life and coping in patients with PD. ${ }^{2-47-15263034-36}$ Our study also confirms an association between coping and quality of life. The well-known fact that emotional forms of coping are associated with a worse health-related quality of life and problem-oriented coping strategies, with a better health-related quality of life, ${ }^{37-13}$ was also evident in our analysis. In the present study, the use of an active coping strategy such as acting/problemoriented coping was associated with better mental quality of life and the use of an emotional coping form such as depressive processing was associated with poorer mental quality of life. An influence of coping on physical quality of life could not be demonstrated.

Coping is the reaction by a person confronted with a stressor to return to a state of homeostasis. Because patients with PD are unable to recover or 'solve' their persisting conditions by themselves, they have to find strategies to adapt to disease-related burden. Patients with PD have to find ways to maintain health-related quality of life. As in our study, active coping is commonly associated with less functional impairment and less depression, while passive coping is associated with greater depression, greater functional impairment and lower general self-efficacy. ${ }^{6}$ Given that $52.5 \%$ of patients with PD in our cohort were assigned to a passive coping strategy, there is an urgent need for strategies or interventions to modify coping strategies. One strategy to promote active and healthy coping is among other the cognitive-behavioural therapy. Cognitive-behavioural therapy has an education and therapeutic component and can be effective in the treatment of depression and anxiety in PD. ${ }^{37}$ With cognitive-behavioural therapy, people can learn to recognise and change maladaptive thinking processes. This can help to gain control over thoughts that may negatively affect their emotions and behaviours. ${ }^{38} 39$ Our study is not free of limitations. The first limitation of this study is its monocentric execution and restriction to a movement disorder unit. This limits the generalisability to community-dwelling people with PD; although, we did not observe coping differences between inpatient and outpatient setting. Second, we did not perform an extensive assessment of personality, because it had already been demonstrated that personality traits such as neuroticism have an impact on stress assessment, the coping process and quality of life in patients with PD. ${ }^{46} 4041$ Third, our study is limited to PD without dementia in order to ensure valid self-report questionnaires. Given that we observed a relationship between cognition and coping in patients with $\mathrm{PD}$, future studies should also include patients with various degrees of cognitive impairment.

\section{CONCLUSION}

The present study has proven that patients with PD use several forms of coping simultaneously. The most commonly used combination was acting/problemoriented coping, and distance and self-promotion, followed by acting, problem-oriented coping and trust in medical care. We have also found that, in addition to the traditional division into active and passive coping, there is an overlapping group in terms of coping with PD. Patients who employ mixed coping strategies are in the transition zone between active and passive coping and differ from those who use a single coping strategy in terms of cognitive impairment, depressive symptoms and duration of disease. Further exploration of mixed coping styles can aid in the implementation of resource-oriented medical and psychological care to maintain well-being in patients with PD in the clinical routine. 
Acknowledgements We thank Eric Winter and Caroline Kamprath for assistance in data collection.

Contributors JDL collected data, performed the statistical analysis and drafted the initial manuscript. TP provided the concept and design of study and was involved in the analysis. OW was involved in interpretation of data. TP and OW revised the manuscript for important intellectual content. All authors read and approved the final manuscript.

Funding TP was supported by a Bundesministerium für Bildung und Forschung grant (01GY1804).

\section{Competing interests None declared.}

\section{Patient consent for publication Not required.}

Ethics approval All procedures performed in studies involving human participants were in accordance with the ethical standards of the institutional research committee (ethics committee of the Jena University Hospital, 4572-10/15) and with the 1964 Helsinki declaration and its later amendments or comparable ethical standards.

Provenance and peer review Not commissioned; externally peer reviewed.

Data availability statement Dataset is available from the corresponding author upon reasonable request for scientific purpose.

Open access This is an open access article distributed in accordance with the Creative Commons Attribution Non Commercial (CC BY-NC 4.0) license, which permits others to distribute, remix, adapt, build upon this work non-commercially, and license their derivative works on different terms, provided the original work is properly cited, appropriate credit is given, any changes made indicated, and the use is non-commercial. See: http://creativecommons.org/licenses/by-nc/4.0/.

\section{ORCID iD}

Tino Prell http://orcid.org/0000-0002-6423-3108

\section{REFERENCES}

1 Haahr A, Kirkevold M, Hall EOC, et al. Living with advanced Parkinson's disease: a constant struggle with unpredictability. J Adv Nurs 2011:67:408-17.

2 Pusswald G, Fleck M, Lehrner J, et al. The "Sense of Coherence" and the coping capacity of patients with Parkinson disease. Int Psychogeriatr 2012;24:1972-9.

3 Hurt CS, Landau S, Burn DJ, et al. Cognition, coping, and outcome in Parkinson's disease. Int Psychogeriatr 2012;24:1656-63.

4 Whitworth SR, Loftus AM, Skinner TC, et al. Personality affects aspects of health-related quality of life in Parkinson's disease via psychological coping strategies. J Parkinsons Dis 2013;3:45-53.

5 Lazarus RS. Coping theory and research: past, present, and future. Psychosom Med 1993:55:234-47.

6 Büssing A, Ostermann T, Neugebauer EAM, et al. Adaptive coping strategies in patients with chronic pain conditions and their interpretation of disease. BMC Public Health 2010;10:507.

7 Bucks RS, Cruise KE, Skinner TC, et al. Coping processes and health-related quality of life in Parkinson's disease. Int J Geriatr Psychiatry 2011;26:247-55.

8 Moore KA, Seeney F. Biopsychosocial predictors of depressive mood in people with Parkinson's disease. Behav Med 2007;33:29-38.

9 Frazier LD. Coping with disease-related stressors in Parkinson's disease. Gerontologist 2000;40:53-63.

10 Backer JH. Stressors, social support, coping, and health dysfunction in individuals with Parkinson's disease. J Gerontol Nurs 2000;26:6-9.

11 Montel S, Bonnet A-M, Bungener C. Quality of life in relation to mood, coping strategies, and dyskinesia in Parkinson's disease. $J$ Geriatr Psychiatry Neurol 2009;22:95-102.

12 Schreurs KMG, De Ridder DTD, Bensing JM. A one year study of coping, social support and quality of life in Parkinson's disease. Psychol Health 2000;15:109-21.

13 Frazier LD. Stability and change in patterns of coping with Parkinson's disease. Int J Aging Hum Dev 2002;55:207-31.

14 Herrmann M, Curio N, Petz T, et al. Coping with illness after brain diseases--a comparison between patients with malignant brain tumors, stroke, Parkinson's disease and traumatic brain injury. Disabil Rehabil 2000;22:539-46.

15 Sanders-Dewey NEJ, Mullins LL, Chaney JM. Coping style, perceived uncertainty in illness, and distress in individuals with Parkinson's disease and their caregivers. Rehabil Psychol 2001;46:363-81.
16 Jagla M, Franke G. Aktives versus passives coping. Drei bekannte Coping-Verfahren Im Vergleich. Behandlungsschwerpunkte in der somatischen Rehabilitation Beiträge zur 31 Jahrestagung des AK Klinische Psychologie in der Rehabilitation 2012.

17 Richter D, Bartig D, Muhlack S, et al. Dynamics of Parkinson's Disease Multimodal Complex Treatment in Germany from 20102016: Patient Characteristics, Access to Treatment, and Formation of Regional Centers. Cells 2019;8:151.

18 Goetz CG, Fahn S, Martinez-Martin P, et al. Movement disorder Society-sponsored revision of the unified Parkinson's disease rating scale (MDS-UPDRS): process, format, and Clinimetric testing plan. Mov Disord 2007;22:41-7.

19 Stebbins GT, Goetz CG, Burn DJ, et al. How to identify tremor dominant and postural instability/gait difficulty groups with the movement disorder Society unified Parkinson's disease rating scale: comparison with the unified Parkinson's disease rating scale. Mov Disord 2013;28:668-70.

20 Szewczyk-Krolikowski K, Tomlinson P, Nithi K, et al. The influence of age and gender on motor and non-motor features of early Parkinson's disease: initial findings from the Oxford Parkinson disease center (OPDC) discovery cohort. Parkinsonism Relat Disord 2014;20:99-105.

21 Nasreddine ZS, Phillips NA, Bédirian V, et al. The Montreal cognitive assessment, MoCA: a brief screening tool for mild cognitive impairment. J Am Geriatr Soc 2005;53:695-9.

22 Visser M, Leentjens AFG, Marinus J, et al. Reliability and validity of the Beck depression inventory in patients with Parkinson's disease. Mov Disord 2006;21:668-72.

23 Morfeld M, Kirchberger I, Bullinger M. SF-36 - Deutsche version des short form-36 health survey: manual. Göttingen: Hogrefe, 2011.

24 Franke G, Franke JM, Jagla M. EFK - Essener Fragebogen zur Krankheitsverarbeitung - Testmanual. Psychometrikon, 2016.

25 Franke G. Dialyse und Lebensqualität - bei Der Fragebogenauswahl die Patientensituation berücksichtigen. Dialyse aktuell 2010;14:278-83.

26 Hurt CS, Thomas BA, Burn DJ, et al. Coping in Parkinson's disease: an examination of the coping inventory for stressful situations. Int J Geriatr Psychiatry 2011;26:1030-7.

27 Haltenhof H, Krakow K, Zöfel P, et al. [Coping behaviors in Parkinson's disease]. Nervenarzt 2000;71:275-81.

28 Krakow K, Haltenhof H, Bühler KE. Coping with Parkinson's disease and refractory epilepsy. A comparative study. J Nerv Ment Dis 1999;187:503-8.

29 Costa FPda, Diaféria G, Behlau M. Communicative aspects and coping strategies in patients with Parkinson's disease. Codas 2016;28:46-52.

30 Lerman SF, Bronner G, Cohen OS, et al. Catastrophizing mediates the relationship between non-motor symptoms and quality of life in Parkinson's disease. Disabil Health J 2019;12:673-8.

31 Pusswald G, Fleck M, Haubenberger D, et al. [What roll does the sense of coherence in coping with Morbus Parkinson play?]. $Z$ Gerontol Geriatr 2009;42:220-7.

32 Ehmann TS, Beninger RJ, Gawel MJ, et al. Coping, social support, and depressive symptoms in Parkinson's disease. J Geriatr Psychiatry Neurol 1990;3:85-90.

33 Anzaldi K, Shifren K. Optimism, Pessimism, coping, and depression: a study on individuals with Parkinson's disease. Int J Aging Hum Dev 2019;88:231-49.

34 Kristofferzon M-L, Engström M, Nilsson A. Coping mediates the relationship between sense of coherence and mental quality of life in patients with chronic illness: a cross-sectional study. Qual Life Res 2018;27:1855-63.

35 Navarta-Sánchez MV, Senosiain García JM, Riverol M, et al. Factors influencing psychosocial adjustment and quality of life in Parkinson patients and informal caregivers. Qual Life Res 2016;25:1959-68.

36 Hurt CS, Burn DJ, Hindle J, et al. Thinking positively about chronic illness: an exploration of optimism, illness perceptions and wellbeing in patients with Parkinson's disease. Br J Health Psychol 2014;19:363-79

37 Egan SJ, Laidlaw K, Starkstein S. Cognitive behaviour therapy for depression and anxiety in Parkinson's disease. J Parkinsons Dis 2015;5:443-51.

38 Lau OWY, Leung LNY, Wong LOL. Cognitive behavioural techniques for changing the coping skills of patients with chronic pain. HKJOT 2002;12:13-20.

39 Wesner AC, Behenck A, Finkler D, et al. Resilience and coping strategies in cognitive behavioral group therapy for patients with panic disorder. Arch Psychiatr Nurs 2019;33:428-33.

40 Pontone GM, Mari Z, Perepezko K, et al. Personality and reported quality of life in Parkinson's disease. Int J Geriatr Psychiatry 2017;32:324-30. 
41 Dubayova T, Nagyova I, Havlikova E, et al. The association of type D personality with quality of life in patients with Parkinson's disease.
Aging Ment Health 2009;13:905-12. 